\title{
A seawater-based open and continuous process for polyhydroxyalkanoates production by recombinant Halomonas campaniensis LS21 grown in mixed substrates
}

Haitao Yue ${ }^{1}$, Chen Ling ${ }^{1}$, Tao Yang ${ }^{1}$, Xiangbin Chen ${ }^{1}$, Yuling Chen², Haiteng Deng ${ }^{2}$, Qiong Wu', Jinchun Chen ${ }^{1}$ and Guo-Qiang Chen ${ }^{{ }^{*}}$

\begin{abstract}
Background: High-cost production of bioplastics polyhydroxyalkanoates (PHA) is a major concern for their large scale application. In order to produce PHA economically, new technology must be developed to reduce costs on energy consumption, fresh water and substrate usages. It is also important to conduct the PHA production process in a continuous way rather than in a batch process.

Results: A halophile Halomonas campaniensis strain LS21 was isolated to allow the development of a sea water based open and continuous process for PHA production utilizing mixed substrates consisting of mostly cellulose, starch, lipids and proteins. To study the feasibilities of open and long-term cultivation as well as genetic manipulation of this strain, polyhydroxybutyrate (PHB), the first member of the diverse PHA family, was taken as an example for the application of H. campaniensis LS21 in a robust and long lasting fermentation process. Wild type and recombinant $H$. campaniensis LS21 containing a PHB synthesis genes phbCAB were allowed respectively to grow in artificial seawater containing mixed substrates similar to kitchen wastes, including soluble and insoluble cellulose, proteins, fats, fatty acids and starch for 65 days without interruption. In the presence of $27 \mathrm{~g} / \mathrm{L} \mathrm{NaCl} \mathrm{under} \mathrm{a} \mathrm{pH}$ around 10 at $37^{\circ} \mathrm{C}$, the recombinant produced approximately $70 \% \mathrm{PHB}$ and the wild type $26 \%$ during the 65 days fermentation process without infection. H. campaniensis LS21 secreted extracellular amylase, lipase, protease and cellulase simultaneously during the whole process to allow consumption of the mixed substrates. The recombinant was also found to stably maintain the phbCAB plasmid over the entire 65 days process.

Conclusions: The seawater based open and continuous process based on halophilic Halomonas campaniensis LS21 allowed the applications of kitchen wastes like mixed substrates as nutrients for production of bioplastic PHB. This study demonstrates the advantages of this technology in terms of energy saving (non-sterilization), seawater based (not fresh water needed), long-lasting and continuous open processing (against batch process), and low cost substrates (non-food mixed substrates). Combined with its ease of genetic manipulation, Halomonas campaniensis LS21 could be developed into a platform for low cost production of chemicals, materials and biofuels.
\end{abstract}

Keywords: PHB, polyhydroxyalkanoates, halophile bacteria, Halomonas campaniensis, mixed substrates, continuous fermentation, open process

\footnotetext{
* Correspondence: chengq@mail.tsinghua.edu.cn

'MOE Key Lab of Bioinformatics, Department of Biological Science and Biotechnology, School of Life Science, Tsinghua-Peking Center for Life Sciences, Tsinghua University, Beijing 100084, China

Full list of author information is available at the end of the article
} 


\section{Introduction}

Industrial biotechnology aims to produce chemicals, materials and biofuels on a large scale using sustainable resources from agriculture [1-3]. By partially replacing depleting petrochemicals, industrial biotechnology should help sustainable development of human society [4-9]. However, most microbial-based industrial biotechnology processes are not competitive enough as they suffer many disadvantages, including high energy-demand due to energy-intensive sterilization processes, heavy consumption of precious fresh water, and batch or fed-batch processing against continuous processes in petrochemical industries. In addition, large-scale production of industrial biotechnology products always consumes a large quantity of agricultural resources, causing some concerns such as food versus fuels et cetera [10-12]. Therefore, it becomes important to develop competitive industrial biotechnology based on energy saving, continuous processing, non-fresh water and non-food substrate consuming processes. Such new technology will allow industrial biotechnology to coexist with chemical industries for supplying chemicals, materials and fuels to a sustainable human society.

Halophile bacteria are able to grow in $\mathrm{NaCl}$. Seawater is rich on $\mathrm{NaCl}$ and it is suitable for halophilic bacteria to grow. Most importantly, 97\% of water on Earth is seawater [13]. With this in mind, it becomes necessary to isolate halophile bacteria that are able to grow rapidly in seawater, utilizing low-cost substrates such as cellulose, starch or kitchen waste. If such bacteria are obtained, a continuous fermentation process should be exploited for reducing process complexity and lowering production cost.

Polyhydroxyalkanoates (PHA) are the most versatile bioplastics with properties similar to petroleum-based plastics $[14,15]$. As a family of biodegradable and biocompatible polyesters, PHA could be developed as environmentally friendly bulk plastics, provided the production cost is competitive $[16,17]$.

Common PHA monomers are 3-hydroxybutyrate (3HB or C4), 3-hydroxyvalerate (3HV or C5), 3-hydroxyhexanoate (3HHx or C6), 3-hydroxyoctanoate (3HO or C8), 3hydroxydecanoate (3HD or C10) and 3-hydroxydodecanoate (3HDD or C12) [17]. These monomers form their homo- or copolymers. Poly(3-hydroxybutyrate) (PHB), Its 4-hydroxybutyrate copolymers P3HB4HB and poly(3-hydroxybutyrate-co-3-hydroxyvalerate) (PHBV) have been well-investigated and also commercialized, yet with limited success due to high production cost [18]. It thus becomes important to develop cost-saving biotechnology for PHA production. As many halophile bacteria can produce PHA $[19,20]$, they could provide a new solution for low-cost PHA production [21-23]. Therefore, PHA production by halophile bacteria can be a convenient example to demonstrate the possibility of a seawater- based continuous fermentation process for competitive industrial biotechnology.

This study aims to isolate a halophile bacterium capable of growing in seawater, utilizing kitchen waste such as mixed substrates. At the same time, as most halophile bacteria are also alkali, a combination of halophile and alkali properties provides a natural anti-infection ability for halophile bacteria, allowing a possible open (unsterile) and continuous fermentation process to occur. If such a halophile bacterium could be found, a convenient example to show its feasibility for industrial biotechnology purposes would be its PHA (or PHB) production. In addition, the halophile bacterium should be allowed to conduct genetic manipulation for production of a wide range of products.

\section{Results and discussion}

The success of this study depends very much on finding a halophile bacterium that is able to grow in seawater at a high $\mathrm{pH}$, utilizing low-value substrates such as cellulose, proteins, starch, fat or fatty acids, or ideally mixtures of these, which are mostly found in kitchen waste. If this halophile and alkali bacterium is isolated, we would be able to develop an unsterile (open) and continuous fermentation process using seawater and mixed substrates for long-lasting production of chemicals, materials or biofuels. Very importantly, the strain should allow genetic manipulations to widen its abilities. To test the above expectations, PHB, a bulk biodegradable plastic, is taken as a convenient example to demonstrate the feasibility of this project.

\section{Isolation and characterization of halophile and cellulose utilizing bacteria}

Among thousands of halophile bacteria isolated from the environmental samples collected from Xinjiang China, five of them were found capable of utilizing cellulose as a sole substrate for accumulating PHB. The five strains were further tested for ability to grow on mixed substrates of cellulose, proteins, fat and starch. Only one strain, termed LS21, demonstrated its ability to utilize the above substrates separately or collectively. Strain LS21 was thus chosen for further study, not only due to its mixed substrate utilization ability, but also its rapid growth and PHB accumulation. Strain LS21 grows well in cellulose medium containing 1 to $20 \%(\mathrm{w} / \mathrm{v}) \mathrm{NaCl}$, indicating it to be a moderate halophile. The optimum $\mathrm{NaCl}$ concentration and temperature for strain LS21 was found to be 4 to $6 \%(\mathrm{w} / \mathrm{v})$ and $42^{\circ} \mathrm{C}$, respectively. No growth was observed below $20^{\circ} \mathrm{C}$ and above $55^{\circ} \mathrm{C}$. The strain grew well in $\mathrm{pH}$ ranging from 5.0 to 11.0, the optimum of which was 10.0. The sequence of $16 \mathrm{~S}$ rRNA gene of strain LS21 was compared with all 16S rRNA encoding gene sequences available in GenBank using the BLAST 
program, results showed that strain LS21 belongs to Halomonas campaniensis (Figure 1A). It is therefore termed Halomonas campaniensis LS21 or H. campaniensis LS21 throughout this study. Based on the BIOLOG experiments result, strain LS21 is urease, oxidase and catalase positive, it hydrolyzes hippurate, Tween 80 and tyrosine, reduces nitrate casein and starch, but is unable to hydrolyze gelatin and phenylalanine. Strain LS21 is unable to grow in medium containing galactose as the only carbon source, whereas sucrose, maltose, cellubiose, mannose, sodium acetate, fructose, glucose and glycerol sustain its growth, respectively. Analysis (16S rRNA) reveals that its sequence shares $100 \%$ similarity to strain Halomonas campaniensis $5 \mathrm{AG}^{\mathrm{T}}$ [GenBank accession number: AJ515365]. Compared strain LS21 with Halomonas campaniensis $5 \mathrm{AG}^{\mathrm{T}}$, two strains exhibit similarities in their phenotypes and physiology. The Accession number of the reference strains of the $16 \mathrm{~S}$ rDNA sequence are provided (Figure 1A, within the parentheses after the strains name).
When grown in glucose mineral medium, both wildtype and recombinant $H$. campaniensis LS21 was found to accumulate only one large PHB granule (Figures $1 \mathrm{~B}$ and $1 C$ ), a phenomenon never observed previously in any wild-type $\mathrm{PHB}$-synthesizing bacteria. Yet this large single PHB granule is convenient for downstream PHB extraction as a large PHB granule size permits an easy centrifugation process due to its relative heavy weight compared with smaller and multiple PHB (PHA) granules commonly found in all other PHA accumulation bacteria $[24,25]$.

\section{Promoter and OriC sequence screening}

H. campaniensis LS21 was identified to be a suitable strain for developing the seawater-based open and continuous process for bulk chemical production utilizing mixed substrates. The next step was the establishment of genetic manipulation methods for increasing the strain's ability. Therefore, we started by screening a native and strong promoter from $H$. campaniensis LS21. When grown under

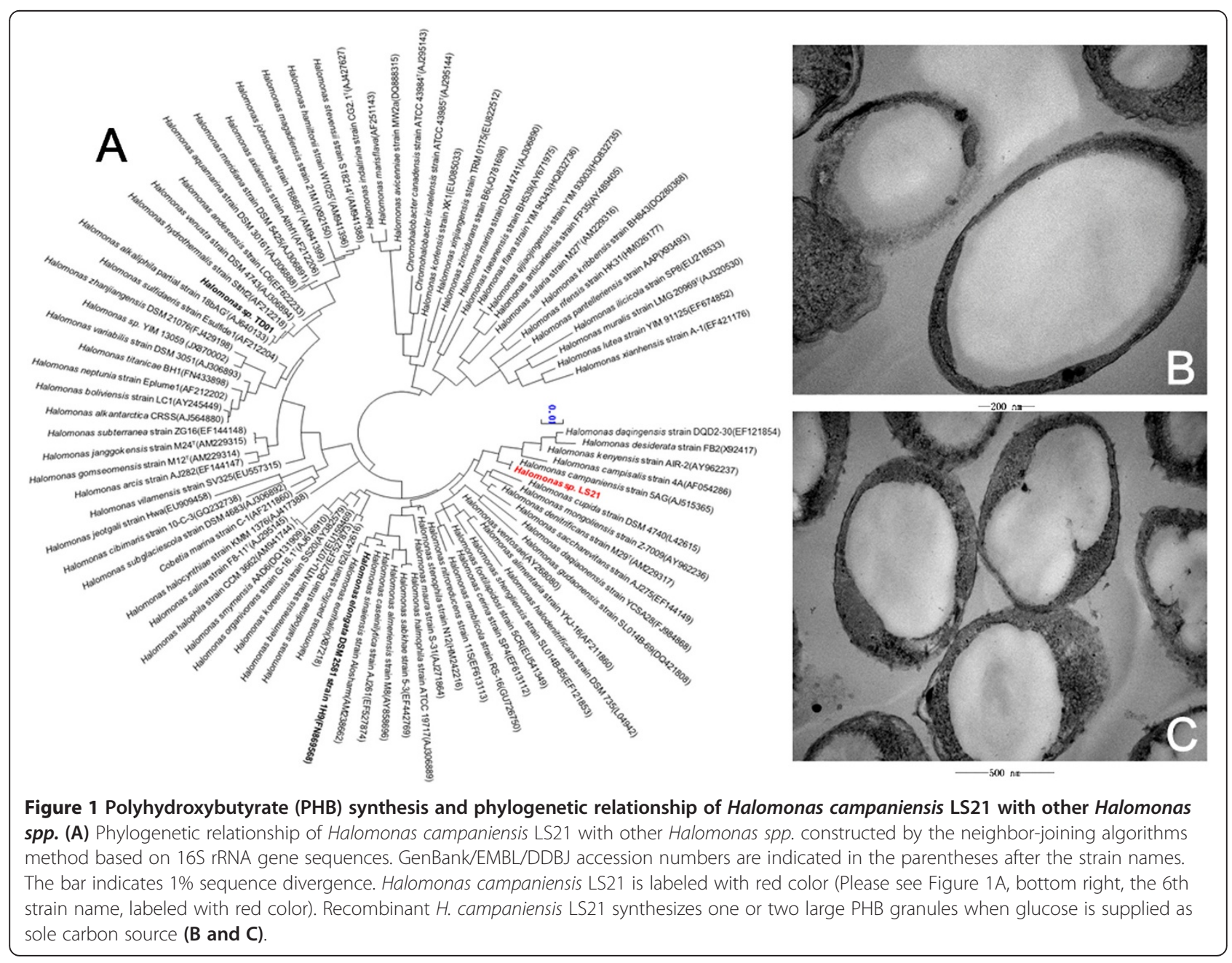


different culture conditions, including cellulose, starch, proteins, fatty acids and LB media ( $10 \mathrm{~g} / \mathrm{L}$ tryptone, $5 \mathrm{~g} / \mathrm{L}$ yeast extract, and $40 \mathrm{~g} / \mathrm{L} \mathrm{NaCl}$ ), respectively, SDS-PAGE analyses on total proteins extracted from the above cultures all showed a very strong band of proteins with a size of approximately $34 \mathrm{KD}$ (Figure 2). The band was revealed to contain 879 types of proteins with similar molecular weights based on the results of protein mass spectra, including methylisocitrate lyase (32.6 KD), Gram-negative bacterial pore protein porin $(39.4 \mathrm{KD})$, transketolase (35.6 KD), and malate dehydrogenase (34.8 KD) as the most abundant proteins. Among this group of similar-size proteins, the porin protein had the highest abundance. This result agrees with others who reported strong constitutively expressed proteins in Halomonas spp [26].

Two genes encoding porin proteins were identified in the genome of $H$. campaniensis LS21 with gene ID HalomonasGL003735 and HalomonasGL001529, respectively. They have a sequence homology of $91 \%$. There are 859 bp and 577 bp distances between HalomonasGL003735 and HalomonasGL001529 and their respective front coding genes according to the promoter predicting software, namely, the Promoter2.0. The software predicted upstream of porin gene HalomonasGL001529 contains multiple promoter sequences. Therefore, the entire upstream sequence of porin gene

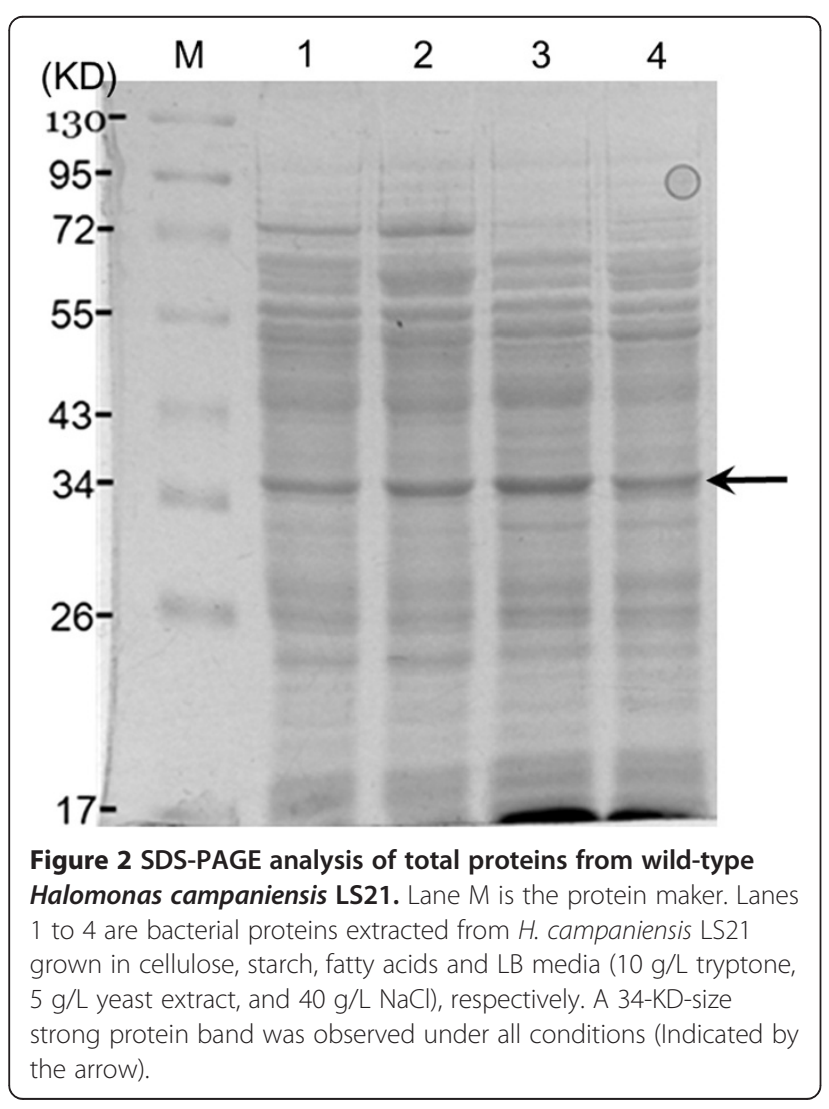

HalomonasGL001529 was selected as a candidate promoter for this study.

Construction of recombinant $H$. campaniensis LS21 and its growth and PHB production study compared with its wild type

Plasmid pBBR1MCS1-OriC-Pporin-phaCAB $B_{\mathrm{LS}}$ was constructed as clearly described in Methods. To improve the PHA synthesis ability of $H$. campaniensis LS21, the plasmid was constructed containing PHB synthesis genes cloned from LS21 including genes of PHA synthase phaC, $\beta$-ketothiolase phaA, nicotinamide adenine dinucleotide phosphate-oxidase (NADPH)-dependent acetoacetyl-CoA reductase $p h a B$, each under a strong porin promoter. It also has an origin of replication OriC from the host chromosome (Figure 1). The pBBR1MCS1-OriC-PporinphaCAB $B_{\mathrm{LS}}$ was first transformed into Escherichia coli S17-1 via electroporation. Conjugation between the above recombinant E. coli S17-1 to H. campaniensis LS21 allowed the plasmid to enter $H$. campaniensis LS21 successfully.

Wild-type and recombinant $H$. campaniensis LS21 were grown in glucose mineral (MMG) medium and mixed substrates medium, respectively. When growth in MMG over a period of $48 \mathrm{~h}$, the wild-type and recombinant cells produced a cell dry weight (CDW) of $8.2 \mathrm{~g} / \mathrm{L}$ containing 57\% PHB and $7.8 \mathrm{~g} / \mathrm{L}$ containing $83 \%$ PHB, respectively. The slow growth of the recombinant was attributed to the presence of chloromycetin $(25 \mathrm{mg} / \mathrm{L})$ which was used to maintain the stability of the plasmid. Obviously, the recombinant accumulated much more PHB compared with the wild type due to the presence of additional PHB synthesis genes (Figure 3 ).

In contrast, when grown in mixed substrates medium over a period of $72 \mathrm{~h}$, the wild-type and the recombinant strains produced a cell dry weight of $4.8 \mathrm{~g} / \mathrm{L}$ containing $19 \% \mathrm{PHB}$ and $4.4 \mathrm{~g} / \mathrm{L}$ containing $63 \% \mathrm{PHB}$, respectively. The growth in mixed substrates was slower compared with that in the MMG. This must be due to the energy the bacteria consumed to produce extracellular hydrolytic enzymes, which hydrolyzed the large molecule substrates for uptake as nutrients. In both cases, the recombinant strain accumulated significantly more PHB than that of the wild-type strain. This confirmed that $H$. campaniensis LS21 can be genetically manipulated to add more possibilities to the strain.

\section{A seawater-based open and continuous process for PHB production using mixed substrates}

Wild-type and recombinant $H$. campaniensis LS21 were grown in mixed substrates composed of straw cellulose extract liquid $200 \mathrm{ml} / \mathrm{L}$ (approximately $0.5 \mathrm{~g} / \mathrm{L}$ cellulose), microcrystalline cellulose $2 \mathrm{~g} / \mathrm{L}$, oleic acid $40 \mathrm{ml} / \mathrm{L}$, animal fat (lard) $5 \mathrm{~g} / \mathrm{L}$, soluble starch $25 \mathrm{~g} / \mathrm{L}$, soya protein $2.5 \mathrm{~g} / \mathrm{L}$ 


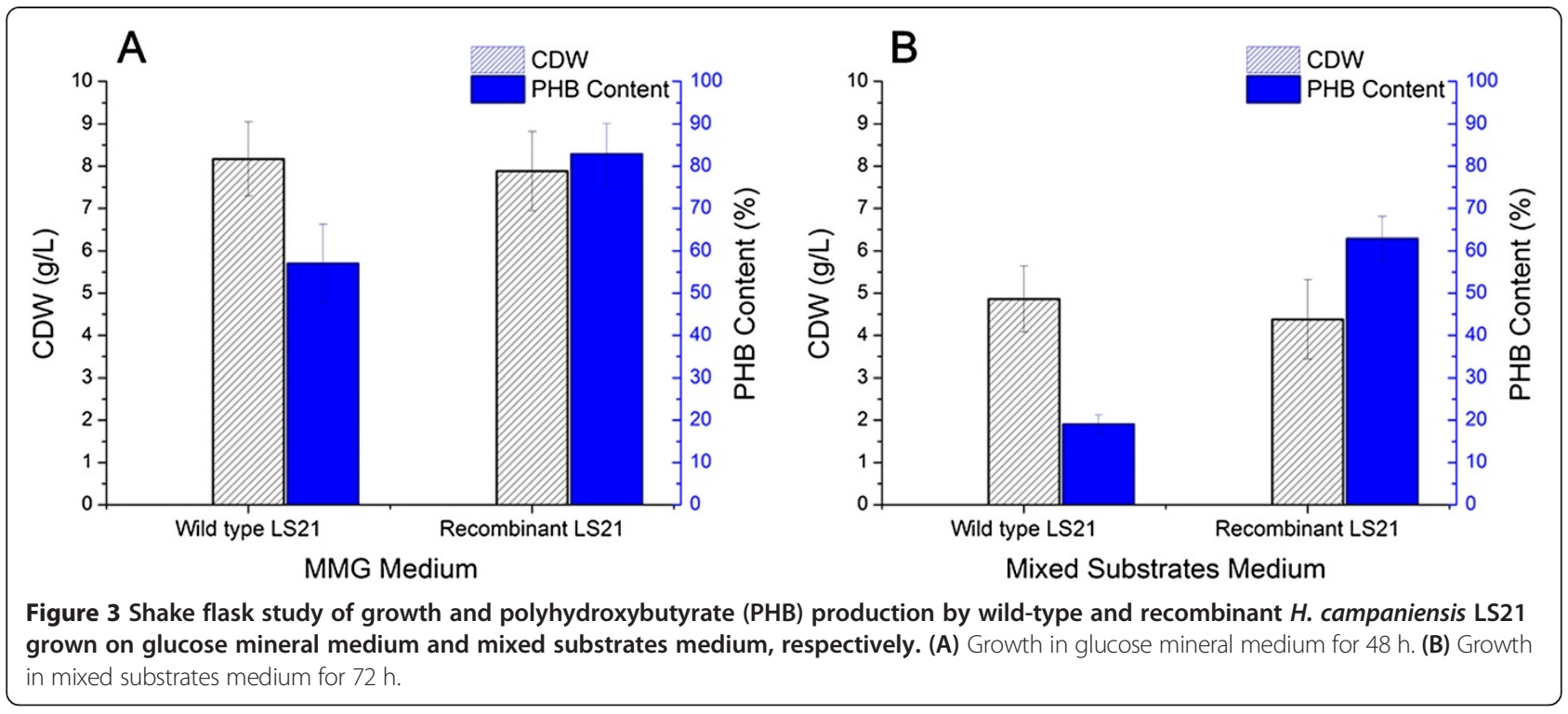

and casein $2.5 \mathrm{~g} / \mathrm{L}$. This composition is similar to many kitchen food wastes. Unlike in shake flasks, wild-type and recombinant cells grew similarly in fermentors with their $\mathrm{CDW}$ reaching the maximum on the day 10 at $73 \mathrm{~g} / \mathrm{L}$ and on the day 12 at $69 \mathrm{~g} / \mathrm{L}$, respectively (Figure 4).

Due to the exhaustion of mixed substrates, especially starch, in both cultures (Figure 5), CDW began to decline for both strains. On days 25 and 49, fresh mixed substrates were added to both cultures, respectively, and cell growth resumed. PHB accumulation seemed to be associated with cell growth for both wild-type and recombinant cells. In all cases, cell growth and $\mathrm{PHB}$ production fluctuated with the availability of starch. Interestingly, amylase activity showed a trend to increase, regardless of the availability of starch (Figure 5A). Both strains consumed fatty acid (oleic acid), proteins

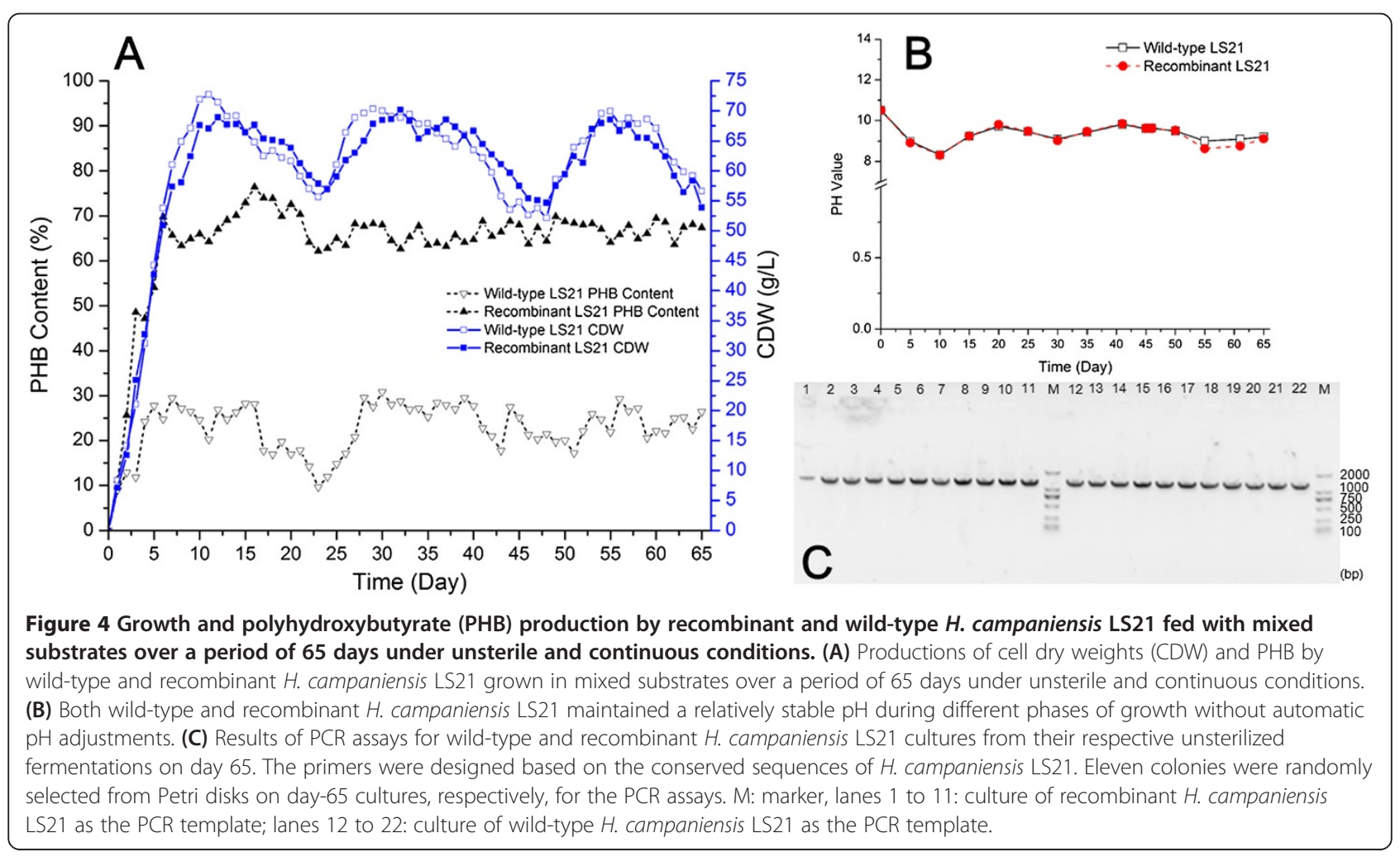




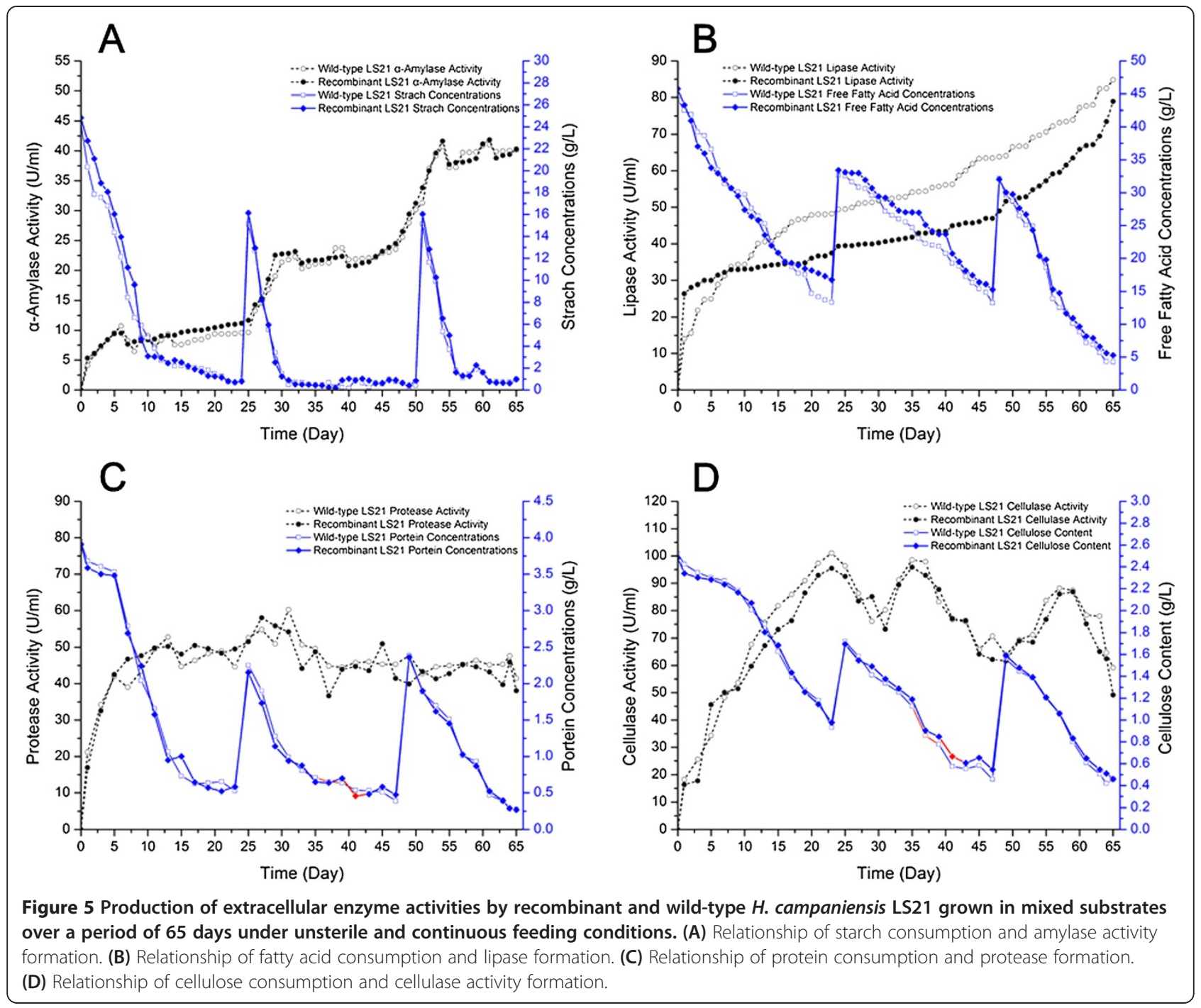

and cellulose but were more sensitive to starch than other substrates.

Although both strains grew similarly, recombinant cells produced far more PHB than the wild-type strain, reaching around $70 \%$ for recombinant and only $30 \%$ for the wild type, demonstrating the stable and strong expression of the PHB synthesis genes by the recombinant $H$. campaniensis LS21. Interestingly, consumption of mixed substrates and formations of amylase, protease and cellulose were always the same for both strains. Remarkably, the wild-type exhibited significantly more lipase activity than the recombinant strain (Figure 5B), resulting in slightly faster fatty acid consumption than the recombinant strain.

In contrast to soluble starch, the mixed substrate medium contained two insoluble components including oleic acid and animal fat (lard). These are more difficult to utilize than starch. The utilization rate of oleic acid and lard by recombinant $H$. campaniensis LS21 was slower than by the wild type (Figure $5 \mathrm{~B}$ ). The concentration of fatty acids decreased to $13 \mathrm{~g} / \mathrm{L}$ (wild-type strain) and $17 \mathrm{~g} / \mathrm{L}$ (recombinant strain) from initially $45 \mathrm{~g} / \mathrm{L}$. The rate of fatty acid consumption was $1.32 \mathrm{~g} / \mathrm{L} \mathrm{d}^{-1}$ and $1.17 \mathrm{~g} / \mathrm{L} \mathrm{d}^{-1}$, respectively. After the second feeding, the two fermentation systems consumed $32.6 \mathrm{~g} / \mathrm{L}$ to $13.2 \mathrm{~g} / \mathrm{L}$ (wild-type strain) and $33.4 \mathrm{~g} / \mathrm{L}$ to $15.2 \mathrm{~g} / \mathrm{L}$ (recombinant strain), respectively. The third feeding led to the highest free fatty acid consumption rate during the growth, which was $1.56 \mathrm{~g} / \mathrm{L} \mathrm{d}^{-1}$ and $1.48 \mathrm{~g} / \mathrm{L} \mathrm{d}^{-1}$, respectively. Similar to the amylase activity change, lipase activity kept increasing during the entire fermentation process (Figure $5 \mathrm{~B}$ ).

We used $4 \mathrm{~g} / \mathrm{L}$ proteins including $2 \mathrm{~g} / \mathrm{L}$ plant soy protein and $2 \mathrm{~g} / \mathrm{L}$ animal casein to imitate soluble and insoluble proteins in food waste. Recombinant and wild-type strains consumed $4 \mathrm{~g} / \mathrm{L}$ proteins to around $0.6 \mathrm{~g} / \mathrm{L}$ on day 17 of the fermentation. Protease activities produced by both strains were maintained relatively stable despite the fluctuation of the protein concentrations (Figure 5C). 


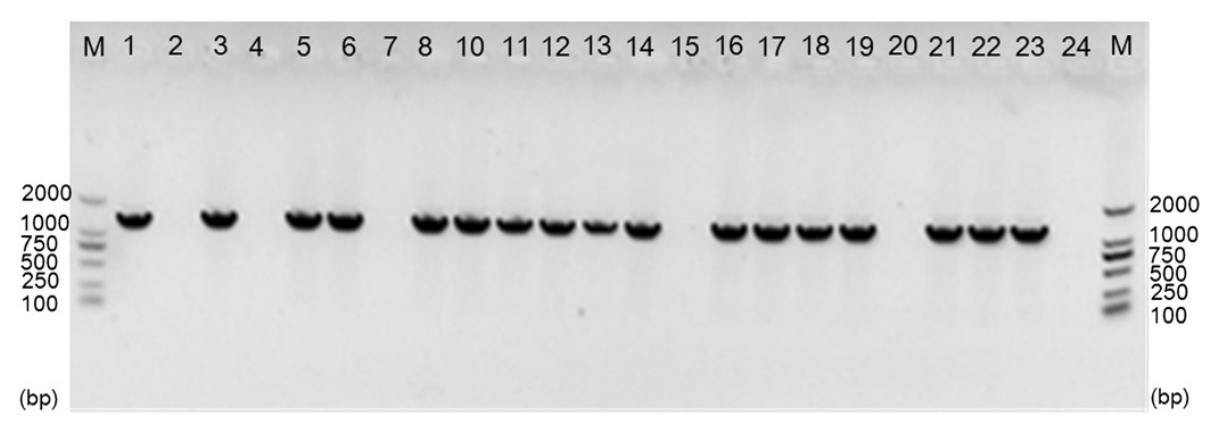

Figure 6 Analysis of plasmid stability based on PCR assays of recombinant $H$. campaniensis LS21 grown under unsterile and continuous process for 65 days. M: marker; lanes 1 to 24: 24 colonies were randomly selected from Petri disks grown with the day-65 recombinant $H$. campaniensis LS21 for the PCR assays. The primers were designed based on the conserved sequence of the backbone plasmid PBBRMCS1 with a target product of $1278 \mathrm{bp}$.

Cellulose was consumed most slowly among the four substrates. Unlike amylase, protease and lipase, cellulase appeared to be sensitive to the availability and concentration of celluose, and decreasing cellulose concentration led to reduced cellulase activity (Figure 5D). The ability of recombinant $H$. campaniensis LS21 to consume mixed macromolecular substrates via the production of extracellular multiple hydrolytic enzymes is an obvious advantage of this strain for industrial biotechnology purpose.

Even after switching off of the automatic $\mathrm{pH}$ adjustment, both wild-type and recombinant $H$. campaniensis LS21 maintained a relatively stable $\mathrm{pH}$ during different phases of growth (Figure 4B). This was due to the mixed substrates consisting of small and larger molecules of different properties, including glucose, amino acids, fatty acids and oligomers of glucose, and amino acids as well as a mixture of the four large molecules, which can provide a buffering effect for the microbial growth system.

Amazingly, results of PCR assays for wild-type and recombinant $H$. campaniensis LS21 cultures from their respective unsterilized fermentation showed an infectionfree phenomenon after the long-lasting 65-day-growth, even though unsterile mixed substrates were fed twice under such robust conditions (Figure 4C), this is almost an ideal situation for any fermentation process engineer.

Plasmid stability is also important for large-scale and long-lasting industrial processes. Analysis of plasmid stability based on PCR assays showed that recombinant $H$. campaniensis LS21 grown under an unsterile and continuous process for 65 days still maintained most their plasmids (Figure 6). On day 65 at the end of the fermentation, $63 \%$ of recombinant $H$. campaniensis LS21 cells still maintained their plasmids.

\section{Conclusions}

A seawater-based open and continuous process based on Halomonas campaniensis LS21 and mixed substrates was developed. It was successfully applied to produce bulk bioplastic PHB. H. campaniensis LS21 was easily constructed into a recombinant that was able to overexpress its native PHB synthesis genes with its own strong porin promoter, resulting in significant enhancement of $\mathrm{PHB}$ accumulation. The process was maintained infection-free under open and feeding conditions for at least 65 days, demonstrating its rare robustness. The ability of $H$. campaniensis LS21 to simultaneously consume several kitchen-waste-like substrates allows industrial biotechnology to avoid the fuel-versus-food issue. Further genetic manipulation should provide a wide range of products to be produced by this process in an economic competitive way.

\section{Methods}

Isolation and identification of moderate halophile-cellulolytic strains

Sludge and plant debris samples were collected from Dabancheng salt lake in Xinjiang, China. All samples were suspended with $1 \%(\mathrm{w} / \mathrm{v}) \mathrm{NaCl}$ aqeuous solution; $1 \mathrm{ml}$ suspension was inoculated into a modified LB medium containing $40 \mathrm{~g} / \mathrm{L} \mathrm{NaCl}$ at $\mathrm{pH} 10.0$ with $2 \%$ agar (40-LB) for first-round isolation of halophile strains. Subsequently, the first-round isolates were inoculated on Petri plates for screening of halophile and cellulolytic strains. The solid plate medium consists of $3 \mathrm{~g} / \mathrm{L}$ microcrystalline soluble cellulose powder (Sigma-Aldrich, Saint Louis, MO, USA) as the sole carbon source, together with per liter $1.5 \mathrm{~g}$ agar and $100 \mathrm{ml}$ of a mineral salt solution containing $0.1 \% \mathrm{NH}_{4} \mathrm{Cl}, \quad 0.2 \% \quad \mathrm{MgSO}_{4}$, $0.12 \% \mathrm{~K}_{2} \mathrm{HPO}_{4}$ (Sinopharm Chemical Reagent Co., Ltd, Shanghai, China). The medium was adjusted to $\mathrm{pH} 10$ with $5 \mathrm{M} \mathrm{NaOH}$ aqueous solution. Plates were incubated at $37^{\circ} \mathrm{C}$ for approximately $48 \mathrm{~h}$. The colony forming units (CFU) that were well-separated were then isolated and purified. One large bacterial isolate with the most rapid growth rate was selected for further characterization. 


\section{Growth characteristics of the isolated strains}

Genomic DNA of the selected strain was purified using EZNA Bacterial DNA Kit (Omega, USA). Then the 16S rRNA gene sequence of the selected strain was determined by sequencing of the PCR-amplified $16 \mathrm{~S}$ rDNA. The $16 \mathrm{~S}$ rDNA was amplified by PCR using standard protocols based on the forward primer-16 F (positions 8 to 27 of the $E$. coli numbering, 5'-GAG TTTGATCCTGGCTCAG-3') and reverse primer-16R (positions 1512-1493, 5'-ACGGCTACCTTGTTACG ACT-3') [27]. The PCR product was purified by EZNA Gel Extraction Kit (TIANGEN, China). Sequencing of 16S rDNA was carried out by BGI (Shenzhen, China). A homology search of the databases was performed using the BLAST program (http://www.ncbi.nlm.nih.gov/BLAST). The phylogenetic tree of $16 \mathrm{~S}$ rDNA was constructed using the neighbor-joining method with MEGA 5.2 software package.

\section{Construction of phaCAB overexpression recombinant H. campaniensis LS21 \\ Promoter screening by quantitative proteomic analysis}

To obtain total bacterial proteins, $H$. campaniensis LS21 was grown to about 1.8 at optical density $(\mathrm{OD})_{600}$, the cells were harvested by centrifugation at $4,000 \mathrm{~g}$ for 15 minutes at $4^{\circ} \mathrm{C}$ from LB liquid medium culture. These cells were re-suspended in $1 \mathrm{ml}$ Tris- $\mathrm{HCl}(\mathrm{pH}=8.0)$, followed by sonication to lyse the cells under ice-cold conditions. The suspension of the lysed cells was centrifuged at $10,000 \mathrm{~g}$ for 15 minutes at $4^{\circ} \mathrm{C}$ to obtain a clear supernatant collected in a clean and sterilized 1.5-ml EP tube. The protein concentrations were studied using bicinchoninic acid (BCA) protein assay [28].

To quantify the target protein under different substrate conditions, samples were separated on 1 D SDS-PAGE. The gel bands corresponding to the targeted proteins were excised from the gel, subsequently reduced with $25 \mathrm{mM}$ DTT and alkylated with $55 \mathrm{mM}$ iodoacetamide [29]. Ingel digestion was carried out using the sequence-grademodified trypsin (Promega, Fitchburg, WI, USA) in $50 \mathrm{mM}$ disodium hydrogen phosphate at $37^{\circ} \mathrm{C}$ overnight. The peptides were extracted twice with $1 \%$ trifluroacetic acid in 50\% acetonitrile aqueous solution for 30 minutes. The extracts were then centrifuged to reduce the volume. Peptides from different samples were labeled with tandem mass tags (TMT) reagents (Thermo, Pierce Biotechnology, USA) according to the manufacturer's instruction. Briefly, the TMT reagents were dissolved in acetonitrile and added to the peptides carefully. The reaction was maintained at room temperature for $1 \mathrm{~h}$, and quenched with 5\% hydroxylamine for 15 minutes. The TMT-labeled peptides were mixed and desalted by stage tips.
To conduct liquid chromatography-tandem mass spectrometry (LC-MS/MS) analysis, the TMT-labeled peptides were separated by a 60 -minute gradient elution at a flow rate of $0.25 \mu \mathrm{l} /$ minute with an EASY-nLCII ${ }^{\mathrm{rm}}$ integrated nano-high performance liquid chromatography (HPLC) system (Proxeon, Denmark), which is directly interfaced with a $\mathrm{Q}$ exactive mass spectrometer (Thermo Scientific, USA). The analytical column was a fused silica capillary column packed with $\mathrm{C} 18$ resin with a dimension of $75 \mu \mathrm{m}$ ID and $150 \mathrm{~mm}$ in length. Mobile phases and A and B consisted of $0.1 \%$ formic acid and $100 \%$ acetonitrile in $0.1 \%$ formic acid, respectively. The $Q$ exactive mass spectrometerwas operated in a data-dependent acquisition mode using the Xcalibur 2.1.3 software. There was a single full-scan mass spectrum in the Orbitrap (400 to $1,800 \mathrm{~m} / \mathrm{z}, 30,000$ resolution) followed by $10 \mathrm{MS} / \mathrm{MS}$ scans in the quadrupole collision cell using the higherenergy collision dissociation.

The MS/MS spectra from each LC-MS/MS run were searched against the selected database using the Proteome Discovery searching engine. The searching parameters are listed below: peptides ms tolerance of 20 ppm; ms/ms tolerance of $20 \mathrm{mmu}$; carbamidomethylation of Cys, TMT of lysine and peptide $\mathrm{N}$ terminal as the fixed modification, oxidation on Met as the variable modification. Peptides with high confidences were used for protein identification. MS/MS spectra for all matched peptides were manually interpreted and confirmed.

\section{OriC sequence screening}

To improve the stability of the plasmid and the efficiency of target gene expression in the bacteria [30], the native chromosomal DNA replication origin (OriC) in H. campaniensis LS21 genome was screened for plasmid construction. Ori-Finder (http://tubic.tju.edu.cn/Ori-Finder), an online system, has been used for finding oriC $H$. campaniensis LS21 genome (with the kind assistance from Professor Zhang Chunting and Dr Gao Feng of Tianjin University, China), which is based on an integrated method comprising the analysis of base composition asymmetry using the $Z$-curve method, distribution of DnaA boxes, and the occurrence of genes frequently close to OriC.

\section{Construction of phaC, phaA and phaB expression plasmid}

To improve the PHA synthesis ability of $H$. campaniensis LS21, an overexpression plasmid of PHA synthesis genes containing genes of PHA synthase phaC, $\beta$ ketothioelase phaA, NADPH-dependent acetoacetyl-CoA reductase $p h a B$ was constructed. The plasmid consists of a porin promoter and an OriC from the host chromosome (Figure 7). In detail, the expression vector pBBR1MCS1OriC-Pporin-phaCAB $B_{\mathrm{LS}}$ applicable in $H$. campaniensis LS21, was constructed by ligating OriC replica and the 


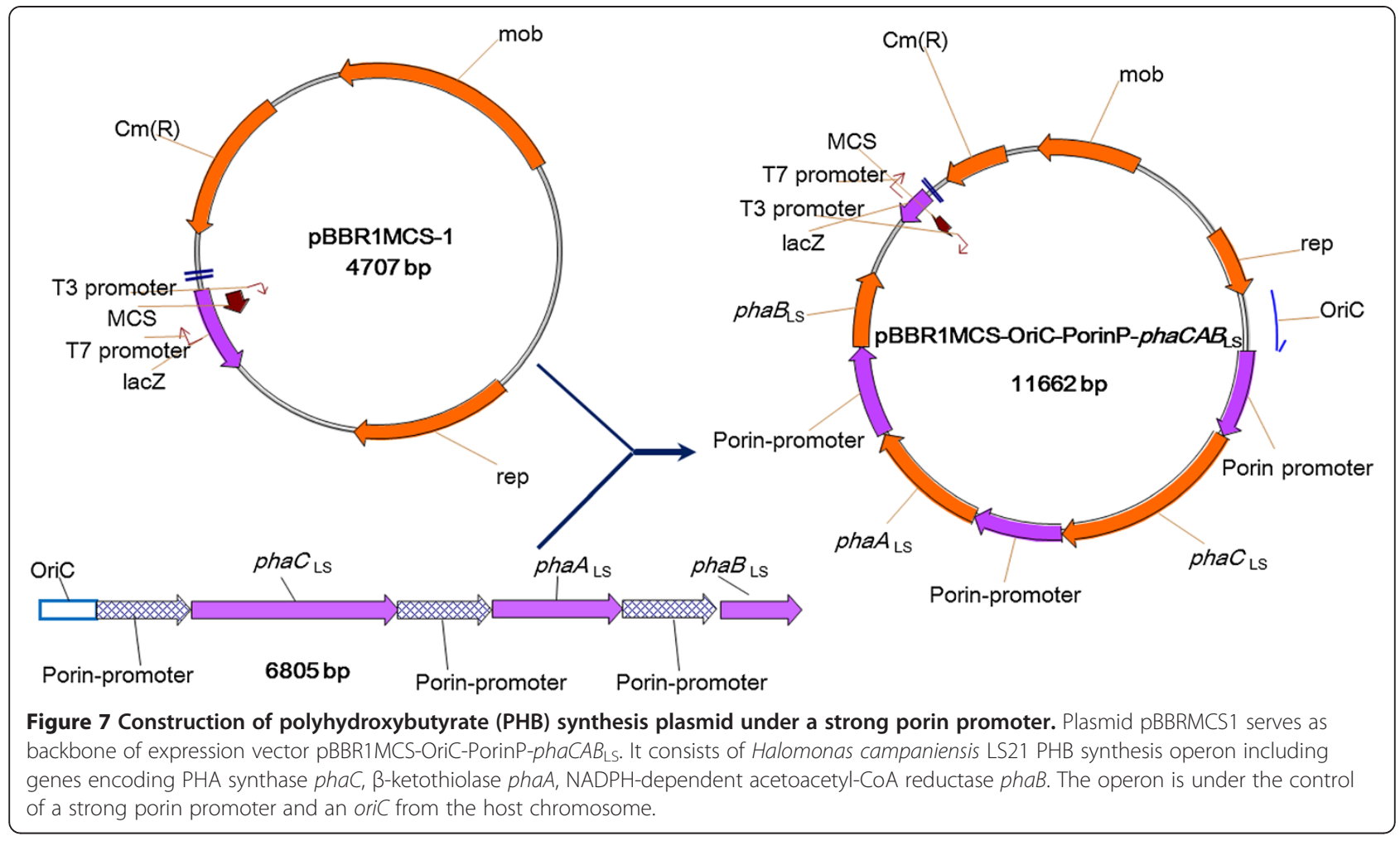

promoter of an outer membrane pole protein termed porin of $H$. campaniensis LS21, which was obtained from the process of promoter screening by quantitative proteomic analysis. Strains and plasmids used in this study listed in Table 1.

Plasmid pBBR1MCS1-OriC-Pporin-phaCAB $B_{\mathrm{LS}}$ was constructed as stated below; five parallel PCR reactions were performed to amplify each target DNA fragment, including phaC, phaB, phaA, OriC and porin promoter sequences, respectively (Table 2). In order to insert multiple copies of porin promoter into the expression vector, the following reactions were divided into three groups including $\mathrm{OriC}+$ porin promoter, $p h a B+$ porin

Table 1 Strains and plasmids used in this study

\begin{tabular}{|c|c|c|}
\hline Names & Descriptions & References \\
\hline \multicolumn{3}{|l|}{ Strains } \\
\hline $\begin{array}{l}\text { Escherichia coli } \\
\text { S17-1 }\end{array}$ & $\begin{array}{l}\text { A conjugation donor, harboring tra } \\
\text { genes of plasmid RP4 in the } \\
\text { chromosome; proA, thi-1 }\end{array}$ & $\begin{array}{l}\text { (Simon } \\
\text { et al., 1983) }\end{array}$ \\
\hline $\begin{array}{l}\text { Halomonas } \\
\text { campaniensis LS21 }\end{array}$ & $\begin{array}{l}\text { Halomonas campaniensis LS21 wild } \\
\text { type, isolated from a salt lake in China }\end{array}$ & This study \\
\hline \multicolumn{3}{|l|}{ Plasmids } \\
\hline pBBR1-MCS1 & $\begin{array}{l}\text { A broad-host-vector that can replicate in } \\
\text { Halomonas TD strain, mobilizable, } \mathrm{Cm}^{\mathrm{R}}\end{array}$ & $\begin{array}{l}\text { (Kovach } \\
\text { et al., 1995) }\end{array}$ \\
\hline $\begin{array}{l}\text { pBBR1MCS1-OriC- } \\
\text { Pporin-phaCAB } A S\end{array}$ & $\begin{array}{l}\text { pBBR1-MCS1 derivate expressing } \\
\text { plasmid, an inducible vector for } \\
\text { phaCAB over expression in Halomonas } \\
\text { LS21 strain, } \mathrm{Cm}^{\mathrm{R}} \text {. }\end{array}$ & This study \\
\hline
\end{tabular}

promoter and $p h a A+$ porin promoter. In each group, equi-molar aliquots of every two adjacent DNA fragments (10 ng for each) mentioned above were mixed as templates to amplify fusion fragments, by overlap extension PCR [31] (primers shown in Table 2, overlap extension PCR part).

Finally, another round of PCR reactions were performed to obtain Gibson assembly fragments, in which three fusion fragments would be needed as templates, namely, OriC + porin promoter, phaB + porin promoter and phaA + porin promoter, phaC sequence and pBBR1MCS1 vector backbone (primers shown in Table 2 used for Gibson assembly). For Gibson assembly [32], 0.1 pmol of each target DNA fragment of OriC-porin promoter fusion fragment, phaB-porin promoter fusion fragment, phaA-porin promoter fusion fragment and phaC fragment, and 0.05 pmoles of vector backbone were added to the reaction system, and $10 \mu \mathrm{l}$ Gibson Assembly Master Mix (New England Biolabs, USA) was required up to $20 \mu \mathrm{l}$ by adding deionized $\mathrm{H}_{2} \mathrm{O}$.

To calculate the number of pmols of each fragment for optimal assembly based on fragment length and weight, we recommend the following formula:

$$
\text { pmols }=(\text { Weightin } n g) \times 1,000 /(\mathrm{bp} \times 650 \text { daltons }) .
$$

The concentration of each fragment was measured using NanoDrop instrument (Thermo Scientific, USA) under absorbance at $260 \mathrm{~nm}$. Incubated samples were 
Table 2 Primers for DNA cloning in this study

\begin{tabular}{|c|c|}
\hline Primers & Sequence $\left(5^{\prime}-3^{\prime}\right)^{a}$ \\
\hline \multicolumn{2}{|c|}{ Fragments amplified } \\
\hline $\begin{array}{l}\text { Porin- } \\
\text { Promoter F }\end{array}$ & CAGTTACTCATGGGTTCC \\
\hline $\begin{array}{l}\text { Porin- } \\
\text { Promoter } \mathrm{R}\end{array}$ & ATGTAGGTTCCTTAACTAGC \\
\hline phaA-F & TAAGCCGCGCTCGCTGTTGGGCAAAG \\
\hline phaA-R & ATTTACAGCTAACAGCGGCGAGCTAGTC \\
\hline phaB-F & CGCTGTTAGCTGTAAATGCTGAGGCG \\
\hline phaB-R & CACAAGTACTTCTCCCCC \\
\hline phac-F & TTCCGACAGCTAAACGCAACTATGTTC \\
\hline phac-R & CAGCGAGCGCGGCTTAGTCCAAGTTTAG \\
\hline OriC-F & TATTGGTTCACTGATTGAGTAAG \\
\hline OriC-R & CGTTAAGCTGTCGGAATTAATCTGACTITITTG \\
\hline \multicolumn{2}{|c|}{ Overlap extension PCR } \\
\hline $\begin{array}{l}\text { PorinP + } \\
\text { phaA F }\end{array}$ & GATAGCGTTGTTATTGTAAGC \\
\hline $\begin{array}{l}\text { PorinP }+ \\
\text { phaA R }\end{array}$ & TGATTGATCCCATTAAAGTAG \\
\hline $\begin{array}{l}\text { PorinP }+ \\
\text { phaB F }\end{array}$ & ACTGGTGGAACTGGTGGA \\
\hline $\begin{array}{l}\text { PorinP + } \\
\text { phaB R }\end{array}$ & ATCCCATTAAAGTAGTTAGC \\
\hline $\begin{array}{l}\text { OriC + } \\
\text { PorinP F }\end{array}$ & TTAATTCTGGTGACCAT \\
\hline $\begin{array}{l}\text { OriC + } \\
\text { PorinP R }\end{array}$ & TCGGAATTAATCTGACTT \\
\hline \multicolumn{2}{|c|}{ Gibson assembly } \\
\hline OriC + P F & CGAGGGGGGGCCCGGTACTGTCGGAATTAATCTGACTTITTG \\
\hline OriC + PR & CATCGTAAACTGTTACCCCCAACCGAG \\
\hline phaC F & GGTAACAGTTTACGATGCGGGAAGCTC \\
\hline phaC R & GATCAATCAATGATGTGCCTGGGCAGA \\
\hline$p h a B+P F$ & GCACATCATTGATTGATCCCATTAAAGTAGTTAG \\
\hline$p h a B+P R$ & GATCAATCAATGCAACTGGATAGCGTTG \\
\hline$p h a A+P F$ & CAGTTGCATTGATTGATCCCATTAAAGTAGTTAGCG \\
\hline$p h a A+P R$ & GAACAAAAGCTGGGTACATGGCCAATCAAGCCCCC \\
\hline
\end{tabular}

placed in a thermocycler at $50^{\circ} \mathrm{C}$ for 60 minutes to allow assembling of the fragments. Transformable S17-1 competent $E$. coli cells were electroporated with $2 \mu \mathrm{l}$ of the assembly reaction.

\section{Plasmid transformation by conjugation}

Plasmid pBBR1MCS1-OriC-Pporin-phaCAB $B_{\mathrm{LS}}$ was first transformed into E. coli $\mathrm{S} 17-1$ via the electroporation method using a Gene Pulser Xcell (Bio-rad, USA). Plasmid DNA was added to the chilled E. coli S17-1 cells just before treatment. The cells were exposed to single electrical pulses of $1.8 \mathrm{kV}$ (corresponding to field strengths of $18 \mathrm{kV} / \mathrm{cm}$ ) with pulse lengths of
5 ms. After electroporation, cells were diluted into $1 \mathrm{ml}$ chilled LB medium and incubated at $37^{\circ} \mathrm{C}$ for $4 \mathrm{~h}$ to allow expression of the antibiotic resistance phenotype. The cells were re-suspended and incubated for 8 to $12 \mathrm{~h}$ at $37^{\circ} \mathrm{C}$ in $40-\mathrm{LB}$ agar plates containing $25 \mathrm{mg} / \mathrm{L}$ chloromycetin.

Plasmid transformation to $H$. campaniensis LS21 was conducted by conjugation between the above recombinant E. coli S17-1 and H. campaniensis LS21. The donor cells were incubated overnight while recipient ones were incubated in the presence of relevant antibiotics to reach an $\mathrm{OD}_{600}$ of 0.8 . Cells were harvested at $5,000 \mathrm{~g}$ under $4^{\circ} \mathrm{C}$ for 10 minutes, then washed once with LB for E. coli S17-1 or 40- $\mathrm{LB}(40 \mathrm{~g} / \mathrm{L} \mathrm{NaCl}$ in $\mathrm{LB})$ for $H$. campaniensis $\mathrm{LS} 21$, followed by mixing at a 2:1 ratio, subsequently the mixed cells were placed on 40 -LB plates at $37^{\circ} \mathrm{C}$ for $8 \mathrm{~h}$. Cells were re-suspended and incubated for 8 to $12 \mathrm{~h}$ at $37^{\circ} \mathrm{C}$ in 40-LB agar plates containing $25 \mathrm{mg} / \mathrm{L}$ chloromycetin.

\section{Assays of cell dry weights (CDW) and PHA contents}

CDW was determined by centrifuging $40 \mathrm{ml}$ of the culture samples at $10,000 \mathrm{~g}$ for 15 minutes. The pellets were washed twice with $100 \%$ alcohol to remove residual fatty acids, and dried at $-75^{\circ} \mathrm{C}$ until a constant weight was obtained. Intracellular PHA contents were analyzed using a gas chromatograph (GC-2014, SHIMADZU, Japan) after methanolysis of lyophilized cells in chloroform [33].

\section{Residual substrate content measurements}

We collected $40 \mathrm{ml}$ of culture from the fermentor, which was then centrifuged at $10,000 \mathrm{~g}$ for 15 minutes. The supernatant was taken, and $5 \mathrm{ml}$ of supernatant each was used for residual substrate assays including oleic acid and protein, respectively; $10 \mathrm{ml}$ supernatant was needed for starch concentration assays. Due to the insolubility of cellulose, the residual cellulose assays were performed using the precipitated biomass after the centrifugation.

Total cellulose assay kits (Megazyme, Ireland) were used for analyzing total residual soluble and insoluble cellulose in the samples. Similarly, total starch assay kits (Megazyme, Ireland) were employed for residual starchcontent studies. Residual free fatty acid concentrations of samples were quantitatively studied using QuantiChrom free acid kits from BioAssay Systems (USA) according to the manufacturer's recommendations. Residual protein concentrations were measured using $\mathrm{BCA}$ protein assay kit (GenStar, China).

\section{Extracellular hydrolytic enzyme activity measurements}

The AZO-Xyloglucan cellulase kit and protazyme AK tablets (Megazyme, Ireland) were used for analyzing activities of cellulase and protease in the cultures, respectively. On the other hand, activities of lipase and amylase were quantified using the commercially available QuantiChrom assay 
lipase kit and QuantiChrom alpha-amylase assay kit from BioAssay Systems (USA) according to the manufacturer's recommendations, respectively.

\section{Unsterile fermentative PHA production using seawater and mixed substrates}

To investigate the PHB accumulation ability of wild-type and recombinant $H$. campaniensis LS21 grown on mixed substrates (especially kitchen waste) consisting mostly of cellulose, starch, animal fats and proteins, a fedcontinuous fermentation process was carried out. The whole process did not involve any sterilization of the fermentors, initial medium and feeding nutrients, or the whole piping system. Instead of the fresh water, artificial seawater was prepared and used during the fermentation process (Table 3 ).

The mixed substrate medium was composed of straw cellulose extract liquid $200 \mathrm{ml} / \mathrm{L}$ (approximately $0.5 \mathrm{~g} / \mathrm{L}$ cellulose), microcrystalline cellulose $2 \mathrm{~g} / \mathrm{L}$, oleic acid $40 \mathrm{ml} / \mathrm{L}$, animal fat $5 \mathrm{~g} / \mathrm{L}$ (lard), soluble starch $25 \mathrm{~g} / \mathrm{L}$, soya protein $2.5 \mathrm{~g} / \mathrm{L}$ and casein $2.5 \mathrm{~g} / \mathrm{L}$. The composition is similar to much kitchen food waste.

Wild-type and recombinant $H$. campaniensis LS21 were each cultured in two 500-ml shake flasks each containing $100 \mathrm{ml} 40-\mathrm{LB}$ medium at $37^{\circ} \mathrm{C}$ for $12 \mathrm{~h}$, respectively: $200 \mathrm{ml}$ of the flask cultures were inoculated into a 6-L fermenter (Bioflo 3000, NBS, USA). The initial working volume and the culture temperature were set at $3.5 \mathrm{~L}$ (containing $25 \mathrm{mg} / \mathrm{L}$ chloromycetin) and $37^{\circ} \mathrm{C}$, respectively. A constant $\mathrm{pH}$ at 10 was maintained by automatic addition of $5 \mathrm{M} \mathrm{NaOH}$. Agitation was started at $200 \mathrm{rpm}$ and increased gradually to maintain dissolved oxygen (DO) of $30 \%$ air saturation: $40 \mathrm{ml}$ of the culture broth was withdrawn every $12 \mathrm{~h}$. On days 7 and 34,

Table 3 Mocledon artificial seawater recipe in this study

\begin{tabular}{ll}
\hline Minerals & Concentration $\mathbf{( g / L )}$ \\
\hline $\mathrm{NaCl}$ & 26.726 \\
$\mathrm{MgCl}_{2}$ & 2.26 \\
$\mathrm{MgSO}_{4}$ & 3.248 \\
$\mathrm{CaCl} 2$ & 1.153 \\
$\mathrm{NaHCO}$ & 0.198 \\
$\mathrm{KCl}$ & 0.721 \\
$\mathrm{NaBr}$ & 0.058 \\
$\mathrm{H}_{3} \mathrm{BO}_{3}$ & 0.058 \\
$\mathrm{Na}_{2} \mathrm{SiO}_{3}$ & 0.0024 \\
$\mathrm{Na}_{2} \mathrm{Si}_{4} \mathrm{O}_{9}$ & 0.0015 \\
$\mathrm{H}_{3} \mathrm{PO}_{4}$ & 0.002 \\
$\mathrm{Al}_{2} \mathrm{Cl}_{6}$ & 0.013 \\
$\mathrm{NH}_{3}$ & 0.002 \\
$\mathrm{LiNO}_{3}$ & 0.0013 \\
\hline
\end{tabular}

Table 4 Primers for testing possible contamination during the open fermentation

\begin{tabular}{lll}
\hline Primers & Sequence $\left(\mathbf{5}^{\prime} \mathbf{-} \mathbf{3}^{\prime} \mathbf{)}\right.$ & $\begin{array}{l}\text { Sizes of target } \\
\text { products }\end{array}$ \\
\hline Halo-test-1708 F & CAATCCTCCCAACACGAC & $1708 \mathrm{bp}$ \\
Halo-test-1708R & CCTGGTAGGCAACAGTGAC & \\
Halo-test-1942 F & GGATGATTCACGGCTAACA & $1942 \mathrm{bp}$ \\
Halo-test-1942R & CCAGGTACATGGACAAGATG & \\
\hline
\end{tabular}

$500 \mathrm{ml}$ artificial seawater was fed to each fermenter vessel within 6 h. On days 25 and 49, 2 L mixed substrates medium including $25 \mathrm{mg} / \mathrm{L}$ chloromycetin was fed to each vessel within $6 \mathrm{~h}$.

\section{Monitoring process microbial contamination using PCR}

Both wild-type and recombinant $H$. campaniensis LS21 cultures from the above fermentations without sterilization were collected, diluted and spread on the Petri plates containing the modified LB medium. The colonies grown on the agar plates were selected randomly for PCR amplification to test possible contaminating microorganisms. The PCR primers (listed in Table 4) were designed according to the whole genome sequence of $H$. campaniensis LS21. Seven sequences was found unique for $H$. campaniensis LS21 according to the BLAST results compared with other strains including Bacillus spp., E. coli and another moderate Halomonas sp., TD01. Based on those sequences, two pairs of specific test primers were designed to amplify the genome of $H$. campaniensis LS21 and the sizes of conserved target products were $1,708 \mathrm{bp}$ and $1,942 \mathrm{bp}$, respectively.

\section{Monitoring plasmid stability using PCR}

Cells of recombinant $H$. campaniensis LS21 sampled after 65 days of fermentation were grown on the agar plates. CFU were selected randomly for PCR amplification to test plasmid stability. The PCR primers (listed in Table 5) were designed according to the pBBRMCS1 plasmid backbone. A pair of specific test primers was designed to amplify pBBRMCS1 backbone with a size of conserved target products around 1,278 bp.

\section{Transmission electron microscope analysis}

Cells were harvested by centrifugation at $10,000 \mathrm{~g}$ for 10 minutes and then prepared for transmission electron microscope analysis as described [34].

Table 5 Primers for testing plasmid stability during the fermentation process

\begin{tabular}{lll}
\hline Primers & Sequence $\left(\mathbf{5}^{\prime}-\mathbf{3}^{\prime}\right)$ & Sizes of target products \\
\hline MCS1-test-1278 F & GCGGATGAATGGCAGAAA $1278 \mathrm{bp}$ \\
MCS1-test-1278R & GGCGAAATGCGAAAGACT & \\
\hline
\end{tabular}




\section{Abbreviations}

BCA: bicinchoninic acid; bp: base pairs; CDW: cell dry weight; CFU: colonyforming units; GC: gas chromatography; H. campaniensis: Halomonas campaniensis; LC-MS/MS: liquid chromatography-tandem mass spectrometry; MMG: glucose mineral medium; NADPH: nicotinamide adenine dinucleotide phosphate-oxidase; phaB: NADPH-dependent acetoacetyl-CoA reductase; OD: optical density; PHA: polyhydroxyalkanoates; phaA: $\beta$-ketothiolase gene; phac: PHA synthase gene; PHB: polyhydroxybutyrate; TMG: tandem mass tags.

\section{Competing interests}

The authors declare that they have no competing interests.

\section{Authors' contributions}

HTY and CL performed the experiments and wrote the manuscript, TY and XBC assisted the long-lasting fermentation studies, YLC and HTD conducted the proteomics analysis. QW and JCC were involved in the conceptual design. GQC designed and supervised this study. All authors read and approved the final manuscript

\section{Acknowledgements}

This collaborative research was financially supported by National Zhicheng Grants (grant number 2012BAD32B02 to JCC) and 973 Basic Research Fund (grant number 2012CB725201 to GQC and number 2012CB725204 to QW), as well as a grant from National Natural Science Foundation of China (grant number 31170099 to JCC). A Sino-Dutch collaborative project entitled "Sustainable biofuel production from organic waste via polyhydroxyalkanoates" also contributed to the project. We acknowledge Professor Zhang Chunting and Dr Gao Feng of Tianjin University for help in OriC sequence screening work.

\section{Author details}

'MOE Key Lab of Bioinformatics, Department of Biological Science and Biotechnology, School of Life Science, Tsinghua-Peking Center for Life Sciences, Tsinghua University, Beijing 100084, China. ${ }^{2}$ Proteomics Facility, center of Biomedical Analysis, School of Life Sciences, Tsinghua University, Beijing 100084, China.

Received: 27 April 2014 Accepted: 18 June 2014 Published: 22 July 2014

\section{References}

1. Vazana Y, Barak Y, Unger T, Peleg Y, Shamshoum M, Ben-Yehezkel T, Mazor Y, Shapiro E, Lamed R, Bayer EA: A synthetic biology approach for evaluating the functional contribution of designer cellulosome components to deconstruction of cellulosic substrates. Biotechnol Biofuels 2013, 6:182.

2. Brás JL, Cartmell A, Carvalho AL, Verzé G, Bayer EA, Vazana Y, Correia MA Prates JA, Ratnaparkhe S, Boraston AB, Romão MJ, Fontes CM, Gilbert HJ: Structural insights into a unique cellulase fold and mechanism of cellulose hydrolysis. Proc Natl Acad Sci USA 2011, 108:5237-5242.

3. Vazana $Y$, Morais S, Barak Y, Lamed R, Bayer EA: Designer Cellulosomes For Enhanced Hydrolysis Of Cellulosic Substrates. In Cellulases, Volume 510. Edited by Gilbert HJ. 2012:429-452.

4. Brethauer S, Wyman CE: Review: Continuous hydrolysis and fermentation for cellulosic ethanol production. Bioresour Technol 2010, 101:4862-4874.

5. Demirbas A: Biodiesel from oilgae, biofixation of carbon dioxide by microalgae: a solution to pollution problems. Appl Energ 2011, 88:3541-3547.

6. Demirbas A: Competitive liquid biofuels from biomass. Applied Energy 2011, 88:17-28.

7. Vyas AP, Verma JL, Subrahmanyam N: A review on FAME production processes. Fuel 2010, 89:1-9.

8. da Silva TL, Gouveia L, Reis A: Integrated microbial processes for biofuels and high value-added products: the way to improve the cost effectiveness of biofuel production. App/ Microbiol Biotechnol 2014, 98:1043-1053.

9. Dusseaux S, Croux C, Soucaille P, Meynial-Salles I: Metabolic engineering of Clostridium acetobutylicum ATCC 824 for the high-yield production of a biofuel composed of an isopropanol/butanol/ethanol mixture. Metab Eng 2013, 18:1-8.

10. Nigam PS, Singh A: Production of liquid biofuels from renewable resources. Prog Energy Combust Sci 2011, 37:52-68.

11. Koizumi T: Biofuel and food security in China and Japan. Renew Sust Energ Rev 2013, 21:102-109.
12. Chen G-Q: New challenges and opportunities for industrial biotechnology. Microb Cell Fact 2012, 11:111

13. Frederiksen HD: The world water crisis: ramifications of politics trumping basic responsibilities of the international community. Int I Water Resour $D$ 2003, 19:593-615.

14. Chen G-Q: A microbial polyhydroxyalkanoates (PHA) based bio- and materials industry. Chem Soc Rev 2009, 38:2434-2446.

15. Keshavarz T, Roy I: Polyhydroxyalkanoates: bioplastics with a green agenda. Curr Opin Microbiol 2010, 13:321-326.

16. Rehm BHA: Bacterial polymers: biosynthesis, modifications and applications. Nat Rev Microbiol 2010, 8:578-592.

17. Chen G-Q: Plastics Completely Synthesized by Bacteria: Polyhydroxyalkanoates. In Plastics from Bacteria: Natural Functions and Applications, Volume 14. Edited by Chen GQ. 2010:17-37. Microbiology Monographs.

18. Gao X, Chen J-C, Wu Q, Chen G-Q: Polyhydroxyalkanoates as a source of chemicals, polymers, and biofuels. Curr Opin Biotechnol 2011, 22:768-774.

19. Van-Thuoc D, Quillaguaman J, Mamo G, Mattiasson B: Utilization of agricultural residues for poly(3-hydroxybutyrate) production by Halomonas boliviensis LC1. J Appl Microbiol 2008, 104:420-428.

20. Quillaguaman J, Delgado O, Mattiasson B, Hatti-Kaul R: Poly(betahydroxybutyrate) production by a moderate halophile, Halomonas boliviensis LC1. Enzyme Microb Technol 2006, 38:148-154.

21. Quillaguaman J, Guzman H, Van-Thuoc D, Hatti-Kaul R: Synthesis and production of polyhydroxyalkanoates by halophiles: current potential and future prospects. Appl Microbiol Biotechnol 2010, 85:1687-1696.

22. Tan D, Xue Y-S, Aibaidula G, Chen G-Q: Unsterile and continuous production of polyhydroxybutyrate by Halomonas TD01. Bioresour Technol 2011, 102:8130-8136.

23. Kawata Y, Shi L-H, Kawasaki K, Shigeri Y: Taxonomic characterization and metabolic analysis of the Halomonas sp KM-1, a highly bioplastic poly(3hydroxybutyrate)-producing bacterium. J Biosci Bioeng 2012, 113:456-460.

24. Potter M, Steinbuchel A: Poly(3-hydroxybutyrate) granule-associated proteins: Impacts on poly(3-hydroxybutyrate) synthesis and degradation. Biomacromolecules 2005, 6:552-560.

25. Kuchta K, Chi L, Fuchs H, Poetter M, Steinbuechel A: Studies on the influence of phasins on accumulation and degradation of $\mathrm{PHB}$ and nanostructure of PHB granules in Ralstonia eutropha $\mathrm{H} 16$. Biomacromolecules 2007, 8:657-662.

26. Tokunaga $\mathrm{M}$, Arakawa $\mathrm{T}$, Tokunaga $\mathrm{H}$ : Recombinant Expression in Moderate Halophiles. Curr Pharm Biotechno 2010, 7:259-266.

27. Lane DJ, Pace B, Olsen GJ, Stahl DA, Sogin ML, Pace NR: Rapid-Determination Of $16 \mathrm{~s}$ Ribosomal-Rna Sequences For Phylogenetic Analyses. Proc Natl Acad Sci USA 1985, 82:6955-6959.

28. Walker JM: The bicinchoninic acid (BCA) assay for protein quantitation. In Methods in molecular biology, Volume 32. Edited by Clifton NJ. 1994:5-8.

29. Li N, Chen Y, Guo Q, Zhang Y, Yuan Y, Ma C, Deng H, Lei J, Gao N: Cryo-EM structures of the late-stage assembly intermediates of the bacterial $50 \mathrm{~S}$ ribosomal subunit. Nucleic Acids Res 2013, 41:7073-7083.

30. Gao F, Zhang CT: Ori-Finder: A web-based system for finding oriCs in unannotated bacterial genomes. BMC Bioinformatics 2008, 9:79.

31. An YF, Ji JF, Wu WF, Lv A, Huang RB, Wei YT: A rapid and efficient method for multiple-site mutagenesis with a modified overlap extension PCR. Appl Microbiol Biotechnol 2005, 68:774-778.

32. Gibson DG, Benders GA, Axelrod KC, Zaveri J, Algire MA, Moodie M, Montague MG, Venter JC, Smith HO, Hutchison CA III: One-step assembly in yeast of 25 overlapping DNA fragments to form a complete synthetic Mycoplasma genitalium genome. Proc Natl Acad Sci USA 2008, 105:20404-20409.

33. Chung AL, Zeng GD, Jin HL, Qiong W, Jin-Chun C, Chen GQ: Production of medium-chain-length 3-hydroxyalkanoic acids by $\beta$-oxidation and phaC operon deleted Pseudomonas entomophila harboring thioesterase gene. Metab Eng 2013, 17:23-29.

34. Denner EBM, Mcgenity TJ, Busse HJ, Grant WD, Wanner G, Stanlotter H: Halococcus salifodinae sp. Nov., an archaeal isolate from an Austrian salt mine. Int J Syst Bacteriol 1994, 44:774-780

\section{doi:10.1186/1754-6834-7-108}

Cite this article as: Yue et al:: A seawater-based open and continuous process for polyhydroxyalkanoates production by recombinant Halomonas campaniensis LS21 grown in mixed substrates. Biotechnology for Biofuels 2014 7:108. 